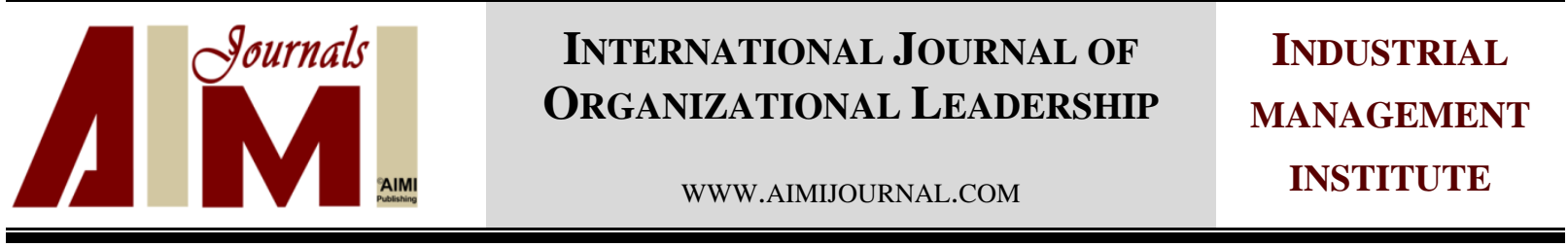

\title{
Specific characteristics of innovation management process
}

\author{
Pouran Yasini \\ Ph.D. Student, Department of in Educational Administration, Faculty of Humanities, University of Garmsar, Iran
}

\begin{tabular}{|c|c|}
\hline & ABstract \\
\hline \multicolumn{2}{|l|}{ Keywords: } \\
\hline $\begin{array}{l}\text { Process of Innovation } \\
\text { Management, Innovation, } \\
\text { Models of Innovation, } \\
\text { Innovation Management }\end{array}$ & $\begin{array}{l}\text { Today, the world is full of dramatic changes. Therefore, the third millennium is known as } \\
\text { the era of creativity, innovation, and entrepreneurship. The pace of useful innovations and } \\
\text { inventions in various fields of scientific, cultural, social, industrial, and technological is } \\
\text { more rapid than at any time in human history. Hence, the current information age is called }\end{array}$ \\
\hline $\begin{array}{l}\text { Received } \\
26 \text { November } 2015\end{array}$ & $\begin{array}{l}\text { the knowledge and ability era. The organizations for their survival require new ideas as } \\
\text { well as exquisite and fresh opinions. Therefore, in order to organizations can survive and }\end{array}$ \\
\hline $\begin{array}{l}\text { Received in revised form } \\
03 \text { February } 2016\end{array}$ & $\begin{array}{l}\text { continue their life; in today's turbulent and changeable world, the spirit of creativity and } \\
\text { innovation should be blown at them. The importance of creativity and innovation is to some }\end{array}$ \\
\hline $\begin{array}{l}\text { Accepted } \\
09 \text { May } 2016\end{array}$ & $\begin{array}{l}\text { extent that human life and civilization are not simply conceivable without them. This paper } \\
\text { aimed at defining innovation to incorporate creativity and innovation in organizations. }\end{array}$ \\
\hline
\end{tabular}

Correspondence:

Yasini44@yahoo.com

(C)AIMI Journals

\section{Introduction}

Innovation is an important concept because all human progress is due to innovation and new findings. To maintain status quo and development of the organizations and avoid their destruction and recession, organizations should keep their innovation. If new ideas do not create, the organizations will ultimately deteriorate. Over the past three decades, the most countries all over the world rely on the innovation and development to overcome the various social and economic problems. So, the organizations which are responsible for developing and implementing must have qualified managers. These managers need an innovation and creative plan to improve their development. Therefore, addressing the issue of innovation requires an appropriate context and culture.

To build a culture of innovation in any organization, the first step is that the managers and employees should believe in it and provide the necessary conditions for emerging organizational culture and 
innovation. The result of innovation culture is that the manpower without relying on governments can share in developing countries.

\section{Innovation}

Innovation defines as a process to change an idea or technique into a new innovative product or service that creates value for the customers. Kanter (1995) defined innovation as a new idea which is used in problem solving and totally contains the formation and the process of accepting new ideas, products, and services. According to Flett (1998), innovation is a high-impact new and useful idea, quick transition to the market, and its usages in the organizations for producing cheaper and better products or better customer services. The concept of innovation was first raised by Schumpeter in 1942. He believed that innovation is associated with economic growth and he introduced it as a new combination of productive resources. Schumpeter proposed four types of innovation; Introduction of New Products, Create New Market, New Resources Supply of Raw Materials and Change of Industrial Organization (Rothwell, 1992).

According to the majority opinion of the experts, innovation is considered as a major source for longterm economic growth. In the absence or lack of innovation, the level of economic growth in developing countries will decline until countries cannot benefit from training in the use of scientific knowledge, improve their professional skills, efficiency, and effectiveness of the labor force, and finally reduce economic growth. Most studies suggest that innovative research helps countries to identify economic orientations industrial sectors and move to the production environment (Kogut \& Zander, 1992). Therefore, entrepreneurial orientation of the organization increases the production rate; so that, the increase in production will affect the economy as a whole and lead to the economic growth (Brown \& Eisenhardt, 1995). The main idea behind the concept of innovation emphasizes that innovation is achieved through the people power in production fosters the economic growth. The impact of human capital on economic growth is remarkable in two aspects. The first aspect refers that if the organizational and environmental conditions remain stable, investments in human resources will generate individual productivity. This kind of perspective is the main axis of the human capital theory and therefore based on it the accumulation of human capital on input and economic growth will be higher and productions can grow faster. Another aspect states that investments through technology transfer can boost the productivity. Generally, it can be claimed that innovation happens when a new invention relates to a product, service, and process on the part of the organization's value chain within the framework of existing standards, regulations, and organizational skills with a good performance management.

The review of literature insists on innovation management which is defined as a set of targeted and systematic efforts in order to provide creativity and innovation in social organizations and business environments and convert them into new products and services with economic and monetary value. Innovation management refers to the set of targeted efforts on the system, so that it provides the field of creativity and innovation in the social organizations and the business environment and makes it into a reliable exchange of goods and services with monetary value.

\section{Innovation Process}

Innovation can be divided into several major parts including entrepreneur manager, individual level, project level, and product efficacy. In entrepreneur manager part manager plays an important role in stimulating innovation and increasing the quality and quantity of the products in organizations. Entrepreneur manager provides the executive and financial policies of a project. On the other hand, the 
project manager invites other individuals from different departments to solve the problems or boost the organizational level (Brown \& Eisenhardt, 1995). Although the entrepreneur manager indirectly involved in creating innovation; direct involvement to control the projects takes him away from his main role and reduces the group performance. Expansive cooperation and manager control reduces the self- autonomy and leads to the waste of time in project progress and also limited control can cause negative effects (Damanpour, 1991). Another part is individual level which has a great significance for implementation of innovation and individuals within an organization. Amibell (1998) stated that innovation is the result of creativity. In addition, the new products and ideas which are formed in working groups are defined as creativity. The next part is project level which refers to possessing extensive communication, increasing the learning opportunities, and having informal relations within an organization that in turns leads to the organizations' success (Damanpour 1991, Imai, Nonaka, \& Takeuchi, 1985). The last part refers to the product efficacy which states that development of new products with reasonable price has several benefits. The new products which are originated from innovation are desirable for customers. Ability to develop the new and attractive products to consumers can increase the demand and thus will increase the production and improve the efficacy of performance (Brown \& Eisenhardt, 1995).

\section{Essential Components of Successful Innovation}

For being an innovative organization, some components should be considered into the account which in absence of each one the innovation process can be disrupted or faced with difficultly. Figure 2 presents these components.

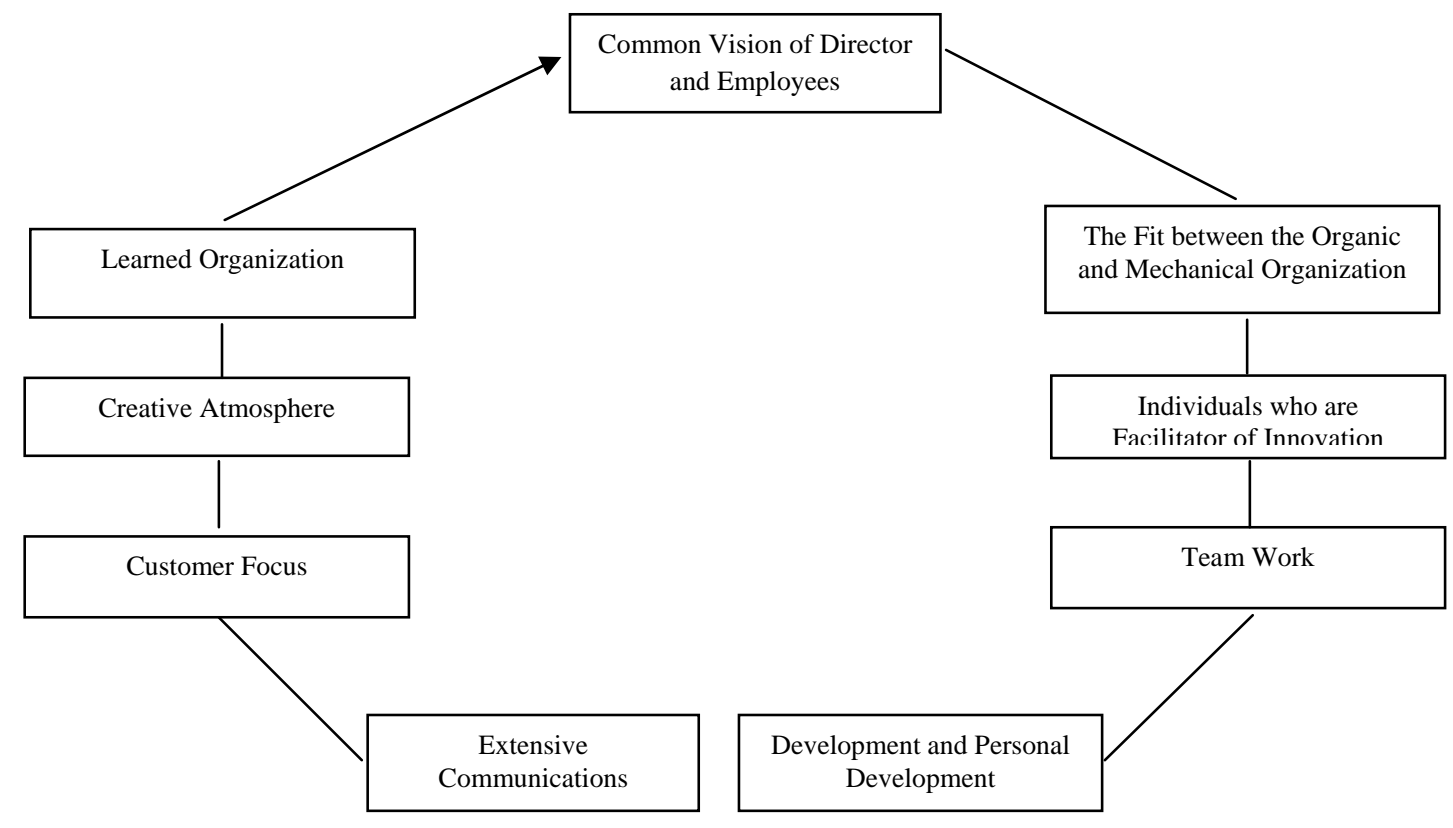

Figure 2. Details of the innovation process

\section{Perfect Environment for Innovation}

Many researchers and experts believe that environmental factors are the driving elements for having creative and innovative behavior. Saunders and Parker (1989) in their study referred to some factors which affect on the operational innovation including knowing and understanding consumer needs, paying attention to product- market fit, developing an efficient innovation, using scientific instruments and techniques, and having a senior executive manager who is responsible for innovation in his 
organization. These environmental factors for innovation include bearing failure, creating a peaceful environment, giving credit to innovators, making creative space, and preparing for change (Ali, 2000).

\section{Innovation Management}

Innovation management refers to the set of critical abilities of director or leader of any organization, because it makes possible for the administrator to create organizational growth and profitability.

One of the contradictions that lies in an innovation is related to the necessity of creating link between unconditional freedom and commitment to discipline. It can be argued that successful organizations are very important in establishing discipline and innovation. It is significant to consider that establishing relationship between discipline and organizational innovation is very difficult for managers. A summary of the research and literature on theorists of creativity and innovation emphasizes on the innovation management and states that some scholars have focused on the vital role of innovation management which can affect all aspects of economic, social, and future business. Innovation is considered as an inevitable path for future businesses to attract all successful and sustainable companies, businesses, products, and services. Today, we cannot be regarded innovation as an opportunity, but requiring as a vital necessity (Rickards \& Moger, 2006). In general, it can be claimed that the innovation management is the process of creating and implementing a work plan which aims to turn inventions into successful innovations. Moreover, inventions can be considered as innovations when modifications have been done on them. As innovations covert into a sustainable competitive advantage, they can create added value for their customers.

\section{Necessity of an Approach to Innovation Management}

The present era is full of innovation in the fields of technology, goods, and services. There are several reasons why the innovation is important (Shah Hosseini \& Kavoosi, 2009). Economic growth is one of the main reasons for innovation approach. The purpose of local economic development is the real rate of Gross Domestic Product (GDP) which innovation helps it to pave the way for economic growth. Innovation can do to foster economic growth and make organizations economically efficient. Moreover, innovative incentives encourage the people to do economic activities and therefore innovative managers are needed. North (1990) believed that they can determine the effective factors on economic growth. The improvement of social welfare

is another important reason for achieving the innovation that is why innovation creates new industries, business in the community (BICT), and also jobs. The process of introducing new products will create jobs and improve the economic status of those who are directly or indirectly involved in the production. So, if innovation process is managed properly; it will fulfill the human needs. With creativity and innovation management, the organizations can be achieved to their increasing revenue and profitability as well. By minimizing costs, organizations will have the opportunity to raise issues relating to their sales (Maital \& Seshadri, 2007).

\section{Basic Approach to Innovation Management}

According to Allen (2003), there are three main approaches to innovation management in the industry including structural, creative, and dynamic.

Structural innovation became famous during the industrial age and its' purpose was providing effective innovation engineering. This type of innovation was used initially by big companies and it emphasized on internal leadership, strategic planning, and effective implementation of ideas compared with other approaches. The second type of innovation is creative innovation which is common in most small organizations and its focus is on the motivational aspects of innovation. The last type of innovation is called dynamic innovation. Actually, this type of innovation is a combination of structural 
and creative approaches. Small and large organizations can benefit from this innovation. In fact, dynamic innovation has borrowed its' strategic thinking and planning from the structural approach (Damanpour, 1992).

\section{Models of Innovation Management}

Companies and organizations focus more on the way of thinking and finding creative solutions within the organization. Therefore, innovation management model is considered as a set of tools and methodologies that will help the organizations to coordinate with a variety of conditions to eliminate the challenges related to the market with a strategic manner. In the field of innovation management, there is a great variety of models in the market such as the models of Carmen, Mario de la Luz, and Salustiano (2006), Friedman, Getoor, Koller, and Pfeffer (1999), and Trott (2005). In Carmen, Mario de la Luz, and Salustiano's model (2006), group study tries to evaluate the impact of strategic vision and the organization's senior team on the innovation in the organization. Innovative and profitable activities are run by business opportunities in an organization. These opportunities include probable profitable positions that senior managers are able to understand and exploit it. When managers are not able to grasp these opportunities or not to exploit them, there will be fewer opportunities for innovation. When the mental power management is not based on flexibility, these specifications will hinder the creativity.

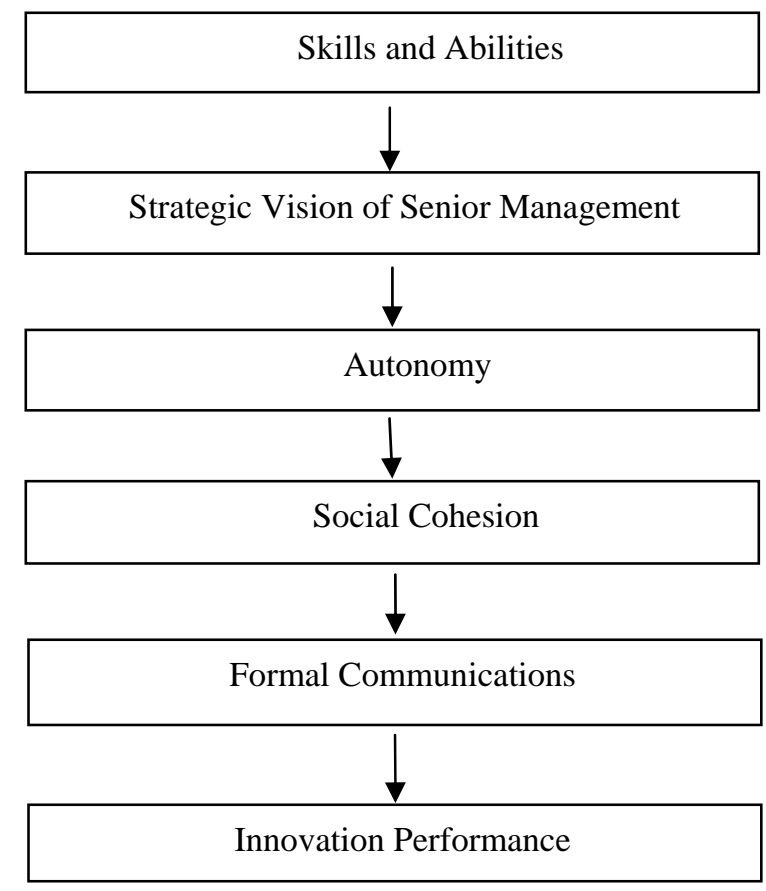

Figure 3. Strategic vision, work- team, and their impacts on innovation

Figure 3 presents the strategic vision, team-work, and their impacts on innovation. A five-sided Friedman, Getoor, Koller, and Pfeffer's model (1999) implies that enterprises and institutions should achieve to their high- performance in five areas to achieve success in the innovation management. These five areas are innovation strategy, creativity and ideas management, selection and portfolio management, performance management, and human resource management. According to this model, the first step in formulating and implementing innovation strategy is to define what innovation means in the organization and its focus areas. By understanding the need for innovation, organizations will be able to develop the innovation. 


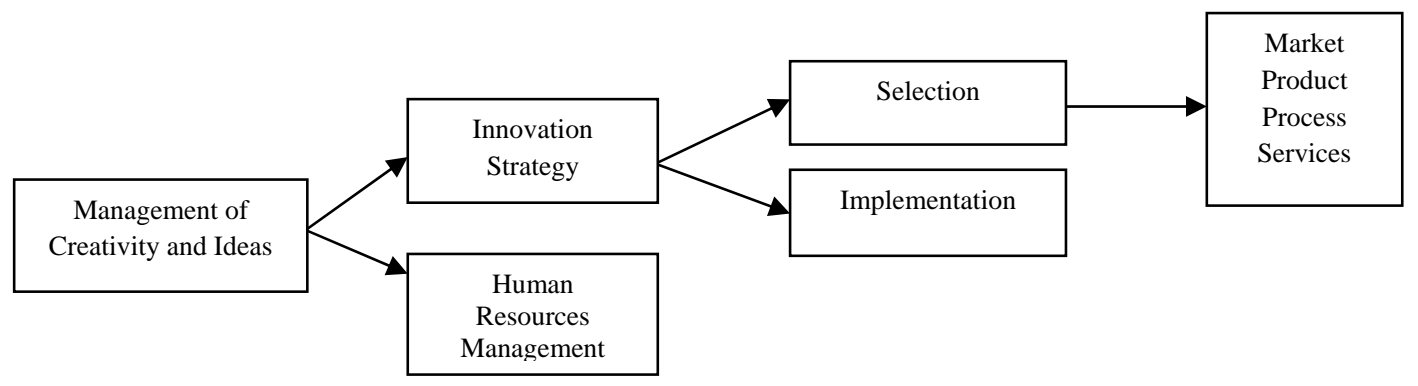

Figure 4. Five-dimensional model of innovation

In order to achieve a desirable level in innovation strategy, it is necessary to express the importance of innovation for employees. The middle section which is management of creativity and ideas, selection and portfolio management, performance management include the necessary processes for innovation development. Innovation development includes the process of creating, selecting, and transferring ideas into commercial products and services. The management of creativity and ideas are incentives ideas that reflect and express the customer's requirements. The scope of the idea should be extended between employees and the ideas must be promoted by the customers. Portfolio selection and management section tries to choose the best ideas from among a large number of the selected ideas for implementation. Implementation is a fundamental capability to transform new ideas into new products, services, or new processes. Human resources management and development deals with people and organizational climate. The purpose of the innovation management is creating an environment in which employees are motivated to participate in innovation. The human factor which is associated with the innovation process is known as a key factor for successful innovation (Oke, 2007). Figure 4 presents the five-dimensional model of innovation.

Table 1

Different Types of Innovation

\begin{tabular}{lc}
\hline Types of Innovation & Example \\
\hline Product Innovation & The Development of a New Product or Improving an Existing Product \\
\hline Innovation Process & Development Process \\
\hline $\begin{array}{l}\text { Organizational Innovation } \\
\text { Innovation Management }\end{array}$ & New Commercial Ventures such as the Creation of a New Accounting policy. \\
\hline $\begin{array}{l}\text { Product Innovation } \\
\text { Business Innovation / } \\
\text { Marketing }\end{array}$ & Comprehensive Quality Management Systems, Re-engineering Business Process \\
\hline Innovation Services & Internet Financial Services \\
\hline
\end{tabular}

According to Trott (2005), recognition of innovative new product development and continuous improvement in an organization is essential. However, in many cases, all innovation elements are in contact with each other (Allard \& Riel, 2005). Table 1 presents different types of innovation.

\section{Innovation Management Framework}

Most of studies by experts and research institutes suggest that innovation management ensures the ability of a country's industry to conquer new markets, products, and services and benefit ultimately from high prices in domestic and international markets in the field of science and technology. 
Therefore, most of the countries that sustain and upgrade their competitiveness are able to create highincome jobs for their citizens. Taking into consideration the various aspects of innovation management, we can outline the general terms related to new innovation management which its purpose is identifying and filling the existing gaps as well as promoting national competitiveness. Figure 5 depicts the innovation management framework.

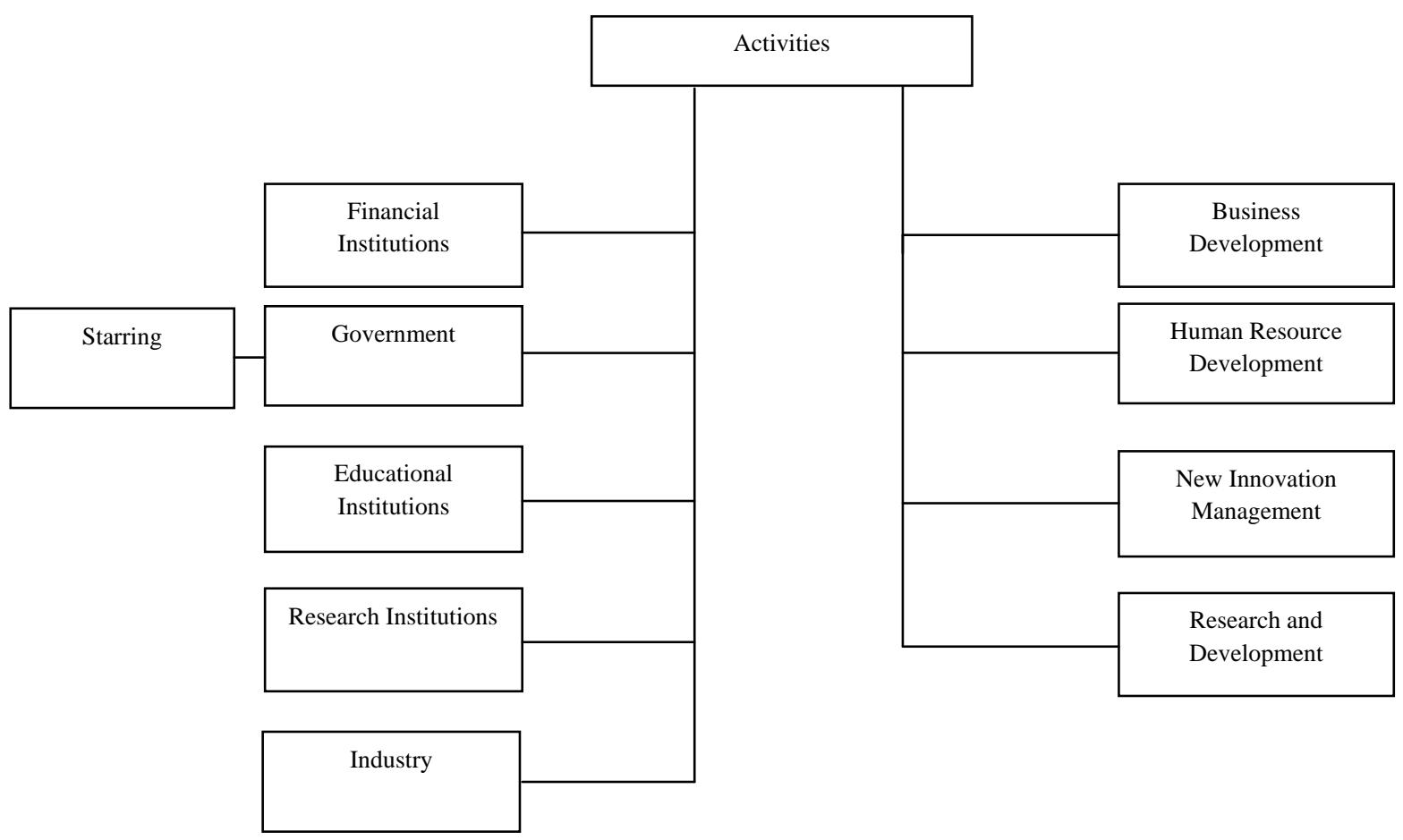

Figure 5. Innovation management framework

According to Figure 5, the main part of this framework is starring of innovation and innovative activities. Innovation plays starring role in industry, government, educational institutions, and research and financial institutions. Innovation activities also include research and development, business development, human resources development, and new innovation management which are followed by starring role for innovation. Innovation management framework assumes that the development of relationships between innovation activities in innovation management system will improve and enhance competitiveness at the national level (Lingela \& Buys, 2007).

\section{Organizational Innovation Process}

Typically, innovation takes place through consecutive actions in the organization. For successfully implementing the innovation process in the organization, the managers need to ensure that all the stages will be carried out respectively in the organization. These stages are the need for change and innovation, comments and ideas, acceptance, execution, and resources. The need for change and innovation is felt when the managers are unhappy about the current performance of the organizations; therefore, the managers must seek and become aware of new methods. Comments and ideas are the new way of doing things; therefore, they can be considered as a model or plan or program that the organization must be implemented. A comment and idea may be implemented within the organization or be entered from outside to inside of the organization. Usually, the comment and idea in the organization should be compared with target requirements. The next stage is acceptance in which the managers are going to 
look back and implement their ideas. To create a change in the organization, the managers and employees must be able to approve it and support the new phenomenon. In execution stage, the organizations' members bring their own new idea, method, and behavior into action. At this stage, the organization must provide all necessary equipments and therefore the employees must also pass new training courses so that they can comment about new ideas and implement them. The last stage which is necessary for innovation is human resources. Innovation requires time and resources for providing new comments and ideas and fulfilling them. The members of organization should consume a lot of energy for fulfilling these two needs. Figure 6 presents the process of innovation which was presented by Daft (1995).

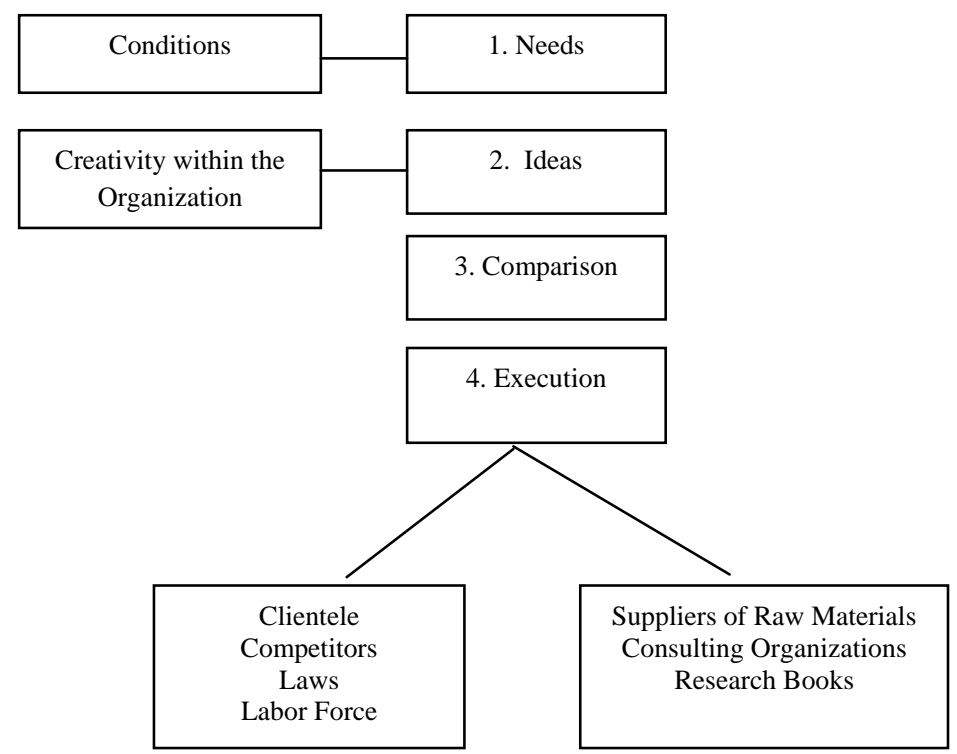

Figure 6. The process of innovation (Daft, 1995)

\section{Characteristics of Innovation Process}

Innovation process has some characteristics. First, innovation process is based on personal knowledge and learning and it can be strengthened by new knowledge. It relies on individual creativity, intelligence, and mutual learning. Due to the speed of new experiences, rapid communication of all those involved in the innovation process is considered necessary. Second, Hesitation is associated with innovation process and creating the massive opportunities for innovation is unpredictable. The results of innovation can hardly be measured with the managers' previous experiences and cannot be expected to provide specific results. Third, innovation process is in contrast to some tasks. Innovation often involves removing some of organizations' activities and placing them in opposite position. Fourth, it goes beyond existing inter- and intra- organizational boundaries. The experimentation and exchange of information are considered as the driver of innovation in different parts of the organization and its outside (Soltani Tirani, 1998).

\section{Concluding Remarks}

Organizations need to have new ideas to survive and achieve the greatest success in the competitive environment of organizations of the third millennium. In this regard, the organizations should pay special attention to people who provide the creative ways. The 
managers should seek opportunities to innovate and finding new ways to improve processes and communications. Thus, innovation is considered as the vital part of optimal facility management. Today, the most important functions of the organizational leaders and senior manager include recognizing the inventive and creative people within the organization and maintaining and motivating them through determining the appropriate substrate. Thus, the organizations can sustain their world markets and finally overcome their competitors through abandoning the traditional methods. Finally, only those organizations that have the ability to create innovation and management innovation can remain in this field and overtake their competitors.

\section{References}

Ali, S. (2000). Managing creativity and innovation in organizations. Tadbir, 110, 59-65.

Allard, C. R., \& Riel, V. (2005). Introduction to the special issue on service innovation management. Managing Service Quality, 15(6), 493-495.

Allen, K. (2003). Bringing new technology to market. Upper Saddle River, NJ: Prentice Hall.

Brown, S. L., \& Eisenhardt, K. M. (1995). Product development: Past research, present findings, and future directions. Academy of Management Review, 20(2), 343-378.

Carmen, C. O., Mario de la Luz, F., \& Salustiano, M. (2006). Influence of top management team vision and work team characteristics on innovation: The Spanish case. European Journal of Innovation Management, 9(2), 179-201.

Daft, R. L. (1995). Organization theory and design (A. Parsaeian \& M. Arab, Trans). Tehran: Cultural Research Bureau.

Damanpour, F. (1991). Organizational innovation: A meta-analysis of effects of determinants and moderators. Academy of Management Journal, 14(3), 555-590.

Damanpour, F. (1992). Organization size and innovation. Organization Studies, 13(3), 375-402.

Flett, F. (1998). Innovation in mature companies-rejuvenation or stagnation? Management Decisions, 27, 51-58.

Friedman, N., Getoor, L., Koller, D., \& Pfeffer, A. (1999). Learning probabilistic relational models. Proceedings of the 16th international joint conference on artificial intelligence (IJCAI), San Francisco, 1300-1309.

Imai, K., Nonaka, I., \& Takeuchi, H. (1985). Managing the new product development process: How Japanese companies learn and unlearn. In R.H. Hayes, \& Clark, K. B. (Eds.), The uneasy alliance: Managing the productivity-technology dilemma (pp. 337-375). Cambridge, Massachusetts: Harvard Business School Press.

Kanter, R. M. (1995). The change masters: Innovation and productivity in the American corporation. New York: Simon \& Schuster.

Kogut, B., \& Zander, U. (1992). Knowledge of the firm, combinative capabilities, and the replication of technology. Organization Science, 3(2), 383-397.

Lee, Y.D., \& Chang, H. M. (2006). Leadership style and innovation ability: An empirical study of Taiwanese wire and cable companies. Journal of American Academy of Business, 9(2), 218-222.

Lingela, V., \& Buys, A. (2007). An innovation management framework to improve national competitiveness in developing countries. Proceedings of the 16th International Association of Management of Technology Conference (IAMOT), Florida, USA, 1572-1593.

Maital, S., \& Seshadri, D. V. R. (2007). Innovation management: Strategies, concepts, and tools for growth and profit. New Delhi: Sage Publications.

Mottaghi, H. A. (2004). Reengineering the inevitable. Tadbir, 144(83), 56-62.

North, D. C. (1990). Institutions, institutional change, and economic performance. Cambridge, MA: Cambridge University Press.

Oke, A. (2007). Innovation types and innovation management practices in service companies. International Journal of Operations \& Production Management, 27(6), 564-587.

Rickards, T., \& Moger, S. (2006). Creative leaders: A decade of contributions from creativity and innovation management. Creativity \& Innovation Management Journal, 15, 4-18.

Rothwell, R. (1992). Successful industrial innovation: Critical factors for the 1990s. R \& D Management, 22(3), 221-238. 
Saunders, D. G., \& Parker, J. C. (1989). Legal sanctions and treatment follow through among men who better: A multivariate analysis. Social Work Research and Abstracts, 25(3), 21-29.

Shah Hosseini, A., \& Kavoosi, I. (2009). Innovation and entrepreneurship. Tehran: Ayizh Publications.

Soltani Tirani, F. (1998). Institutionalization of innovation in the organizations ( ${ }^{\text {nd }}$ ed.). Tehran: Rasa Cultural Services Publication.

Torrington, D., Weightman, J., \& Jones, R. (1989). Effective management: People and organization. London: Prentice Hall.

Trott, P. (2005). Innovation management and new product development. England: Prentice Hall. 